\title{
QASER AL KHARANH A CIVILIZE MONUMENT BETWEEN CONSERVATION METHODOLOGY AND IT'S LOST
}

\author{
قصر الخرانة معلم حضاري بين منهجية الحفاظ وضياع المعلم

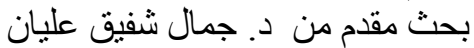

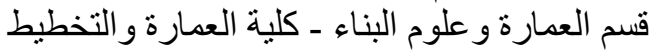

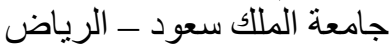 \\ عضو المجلس العالمي للمعالم والمو اقع ICOMOS - باريس
}

(Received July 28, 2008 Accepted August 25, 2008)

The purpose of this research is to investigate and analyze the Umayyad desert castles that are located in Jordan between Amman and Azraq.

It was historically considered as a connecter of the caravanserais that were going between Damascus, Baghdad and Hijaz. Qaser al Kharanah is considered as a significant architectural monument that represents an important period of the Umayyad civilization.

This castle is now deteriorated because of two reasons, weather conditions and lack of established strategy of conservation.

The Department of the Antiquity started doing some restoration jobs that were not based on scientific bases which causes more damage and deterioration.

This research is representing a new methodology for conservation. The results indicate that this strategy is appropriate and will be helpful to present this monument and could be applied in other historical sites.

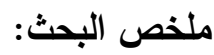

قصر الخرانه هو قصر أموي في وسط الطربق بين عمان والازرق، وتاريجيا كان عبارة عن حلقة وصل مهمة على طريق قوافل يصل بين دمثق وبغداد ومدن الحجاز ، ضمن منظومة لقصور بني امية كمحطات استراحة بين اجزاء الخلافة المههة.

قصر الخرانة معلم معماري يمثل عمارة فترة تاريخية مهمة من الحضارة الاموية في الاردن خاصـة، وفي عمارة المسلمين عامة، وهي من العمارة النادرة الوجود بسبب اندثار معظم المباني التي تعود لتلك الفترة. بالاضـافة الى وضـع القصـر المهلهل بسـبب عوامـل التعريـة، قامـت دائرة الأثار العامـة باعمـال ترميم للقصـر، لكنهـا ليسـت مدروسـة ولا ممنهجـة، ممـا ادى الى زيـادة مظـاهر التلف فيـه ممـا ينـزر بضـياع المعلم.

يهدف البحث الى طرح منهجية للحفاظ على القصر تعتمد على اسس علمية لوضـع حلول منطقية تعتمد على ما جاء في المواثيق العالمية للحفاظ المعماري. 
وينتهي البحث بنتائج وتوصيات تصب في تحقيق الهدف الذي تم رسمه من حيث توضيح المنهجية التي

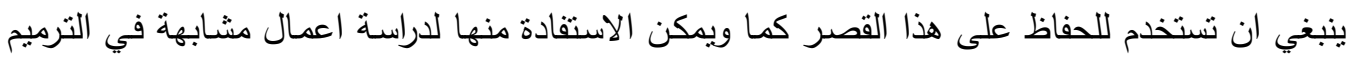
المعماري.

اشكالية البحث: يعاني القصر في الوضع الراهن من مشكلتين أساسيين هما التردي الانشائي أولا، حيث يعاني حاليا من

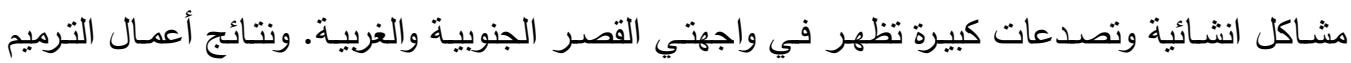

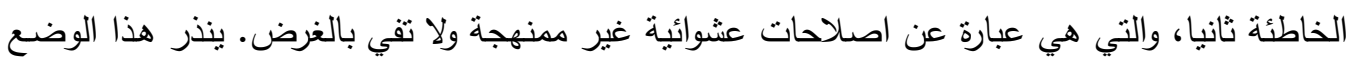
بضياع المعلم بكامله بعد ضياع الكثير من أجزائه ومن قيمه النقافية.

أهداف البحث:

- - - فهم القيم الثقافية الكامنة في المعلم وخاصة القيمة التاريخية. - - فهم عمارة القصر وعلاقته بالقصور الاموية في تلك الفترة. - - فهم علاقة القصر بالبيئة المحيطة به. -

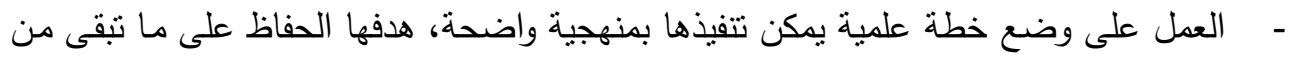

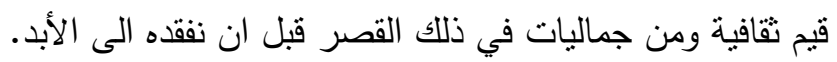

منهجية البحث:

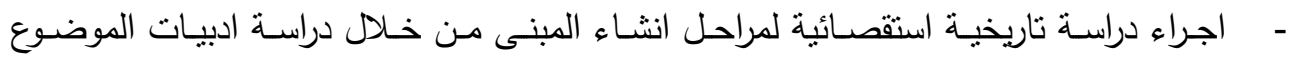

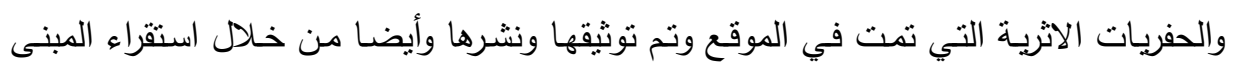

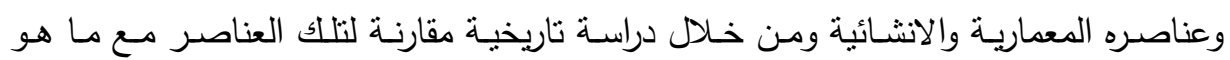
موجود في قصور أموية موجودة في نفس المنطقة. - - تحليل القيم الكامنة في المعلم وتحديد الاهميات. - - نطور التصدع والضعف في المبنى وفهها عبر العامل الزمني. - - دراسة تنخيصية عامة لوضع التصدعات وتاثيرها على سلامة المبنى. - وضع خطة ممنهجة لترميم المعلم، ضمن المعايير العلمية العالمية للترميم.

قصر الخرانة معلم حضاري قصر أموي يقبع في الصحراء الأردنية على بعد 60 كيلو مثر عن عمان في وسط الطريق بين عمان والأزرق وهو عبارة عن حلقة وصل مهمة على طريق القوافل الذي كان بصل بين دمشق والكوفة ومدن الحجاز (مكة والمدينة)، لقد جاء إنشاء هذا القصر ضمن منظومة لقصور بني أمية (من دمثق إلى 
بصرى إلى قصر عمان ثم الموقر وقصير عمرة إلى قصر الأزرق ويتجه (أنظر الثكل رقم 1) جنوبا مرورا بدومة الجندل وهناك يتفرع الطريق باتجاهين جنوبا إلى الحجاز وشرقا إلى البصرة والكوفة) لقد بنيت القصور المذكورة (ليست جميع قصور بني أمية كانت لهذا الهدف1) كمحطات استراحة لرحلات

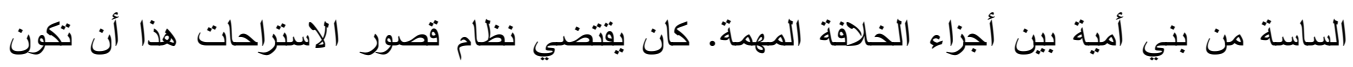

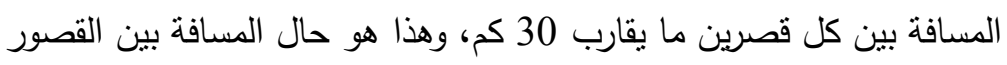

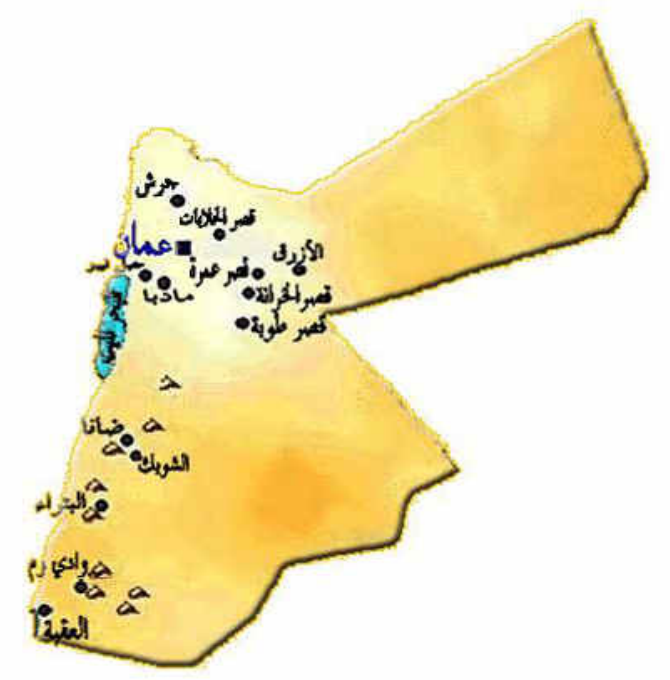

شكل رقم 1 المملكة الاردنية الهاشمية، موقع قصر الخرانة [1].

المتبقية من هذا النظام (عمان والموقر والخرانة وعمرة والأزرق)، لذا يمكنا أن نستتنج عدد القصور

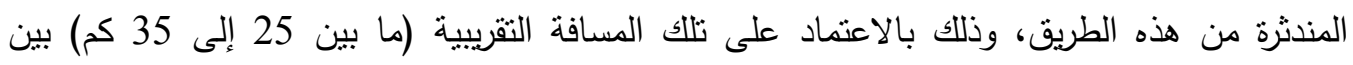
محطات الاستراحة، وهي المسافة التي تقطعها القافلة بمسيرة نهار اليوم وتحتاج بعدها لمأوى واستراحة وأمان ونوم لليلة ذلك اليوم. وما زال موقع قصر الخرانة ذا أهمية لأنه واقع حاليا على الطريق الدولي الذي يربط الأردن بالسعودية والعراق.

تأتي الحضارة الإسلامية الأموية لتوحد نتائج ثقافة معمارية لحضارتين متتاحرتين فيما بينهما في بوتقة

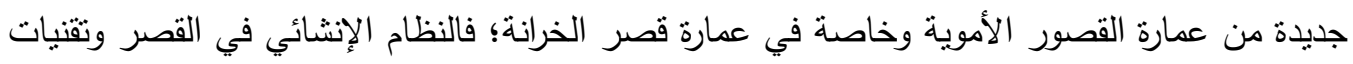

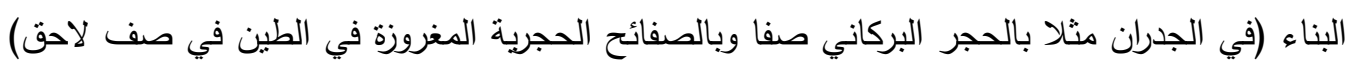

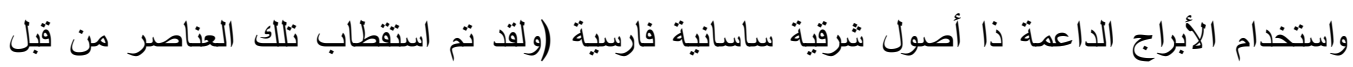

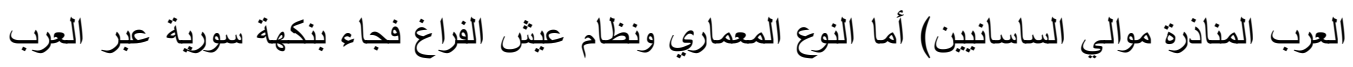

1 كانت هناك قصور أخرى لبني أمية في بلاد الثام بنيت للاستجمام والراحة و التسلية كما كانت هناك قصور أنشبه بالخانات

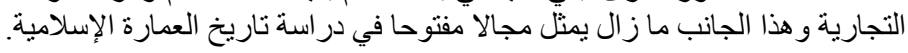


الغساسنة موالي البيزنطيين. ومما يثبت الاستتناج ما جاء من نتائج حفريات ستيفن يوريس Stephen) Urice)

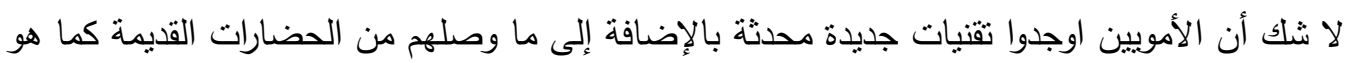

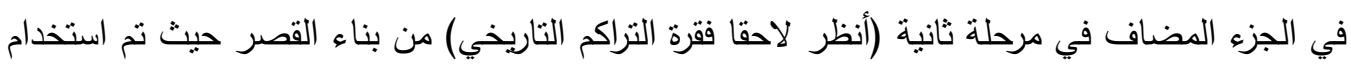

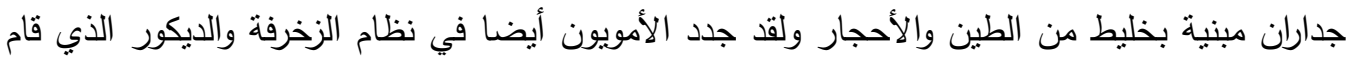
على أسس نباتية تجريدية مرجعيتها سعف النخيل.

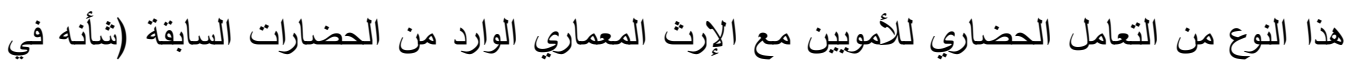
ذللك شان التعامل مع العلوم الأخرى الواردة من الأقدمين) واستخدامه وتطويره والزيادة عليه لتأصيل

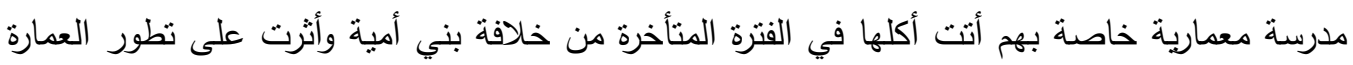

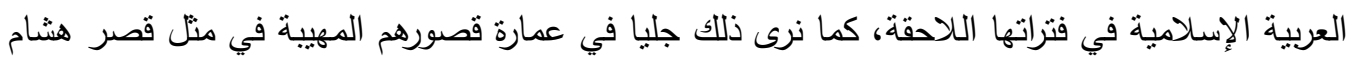
بن عبد الملك في أريحا وقصر المشتى في جنوبي مدينة عمان، حيث أصبح لها شخصية معمارية خاصة بها من حيث ثقنيات البناء بالحجر والطابوق ومن حيث أساليب الاستخدام الوظيفي للفراغات

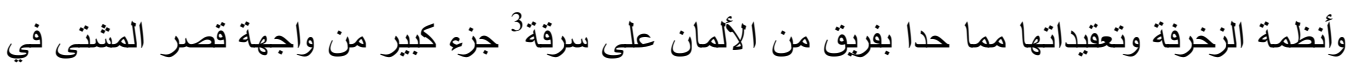

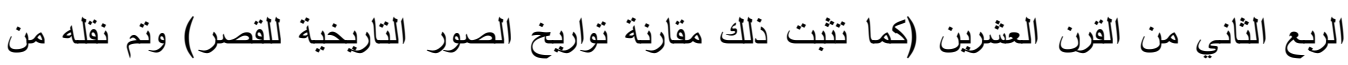

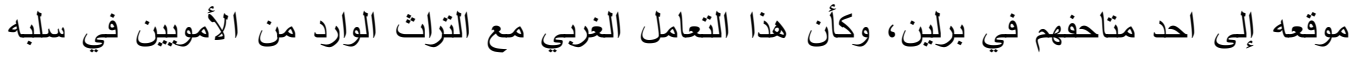

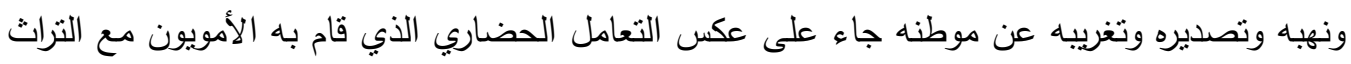

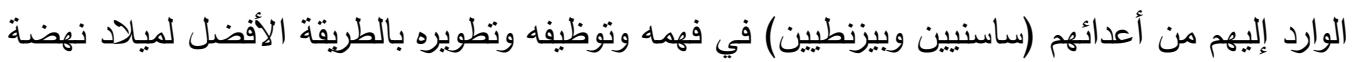
معمارية وثقافية وحضارية إسلامية جديدة. الزخرفة في واجهة قصر المشتى المسروقة تعتبر حجر زاوية في أسس تصميم الزخارف الإسلامية

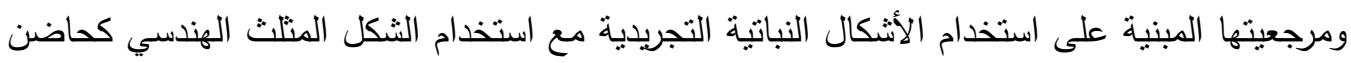
وموزع لها.

عمارة القصر

قام ستيفن يوريس بحفريته خلال عامي 1979 - 1980 م. وكان كتابه الدذكور عملا قيما جاء نتاج عمله البحثي من تحليل

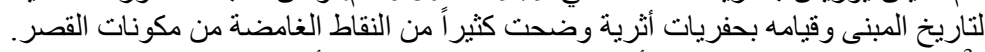

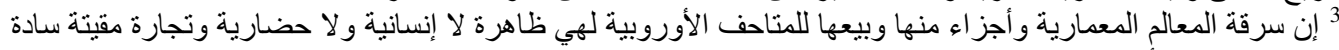

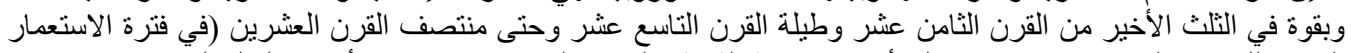

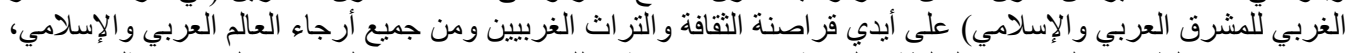

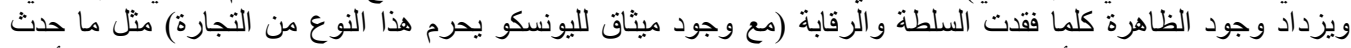

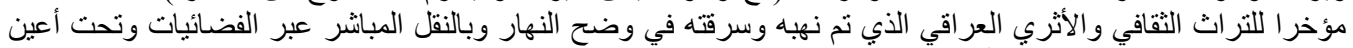
آلات التصوير في فترة الحرب الأخيرة وفيماً بعدها. 
قصر الخرانة مربع التخطيط بمقاييس 34.50 X 36.20 مترا وبارتفاع 9.80 مترا، على زواياه الأربع

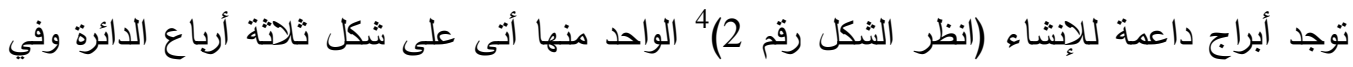
وسط جدرانه الخارجية هناك أبراج داعمة أيضا أتت على شكل أنصاف دوائل دوائر ، ما عدا الواجهة الجنوبية

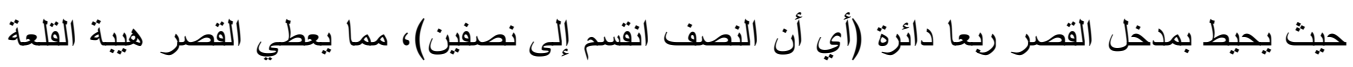

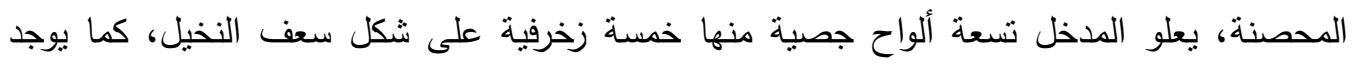

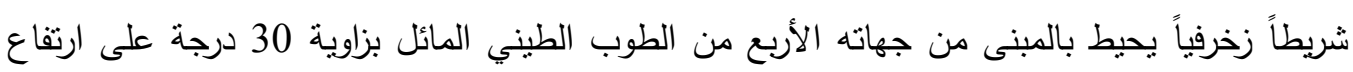

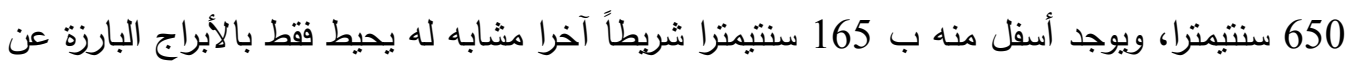
الجدران تأكيدا بصريا على هيبتها وأهينها.
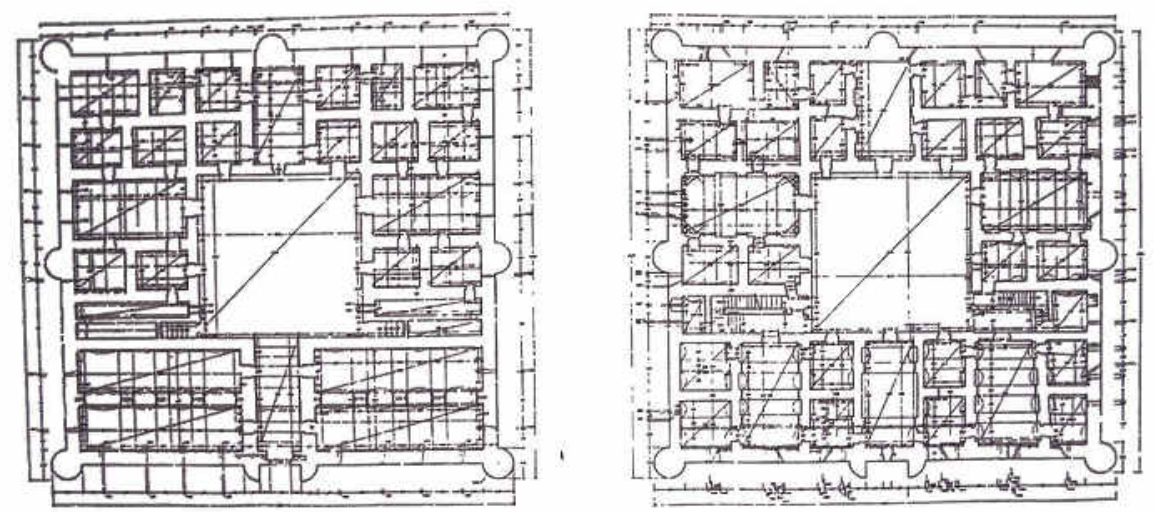

شكل رقم 2 أ،ب. قصر الخرانة، رفع هندي منري، مسقط أفقي للطابق الأرضي ومسقط للطابق الأول.

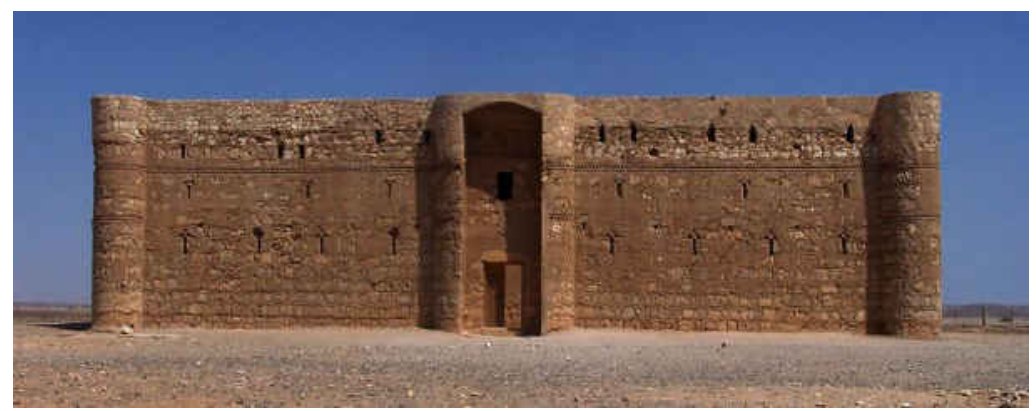

شكل رقم 2ج. قصر الخرانة، الواجهة الجنوبية الرئيسية

4 ملاحظة: جميع الأشكال من عمل الباحث ما لم يذكر خلاف ذلك. وجميع الصور المدرجة في البحث تم التقاطها من قبل الباحث في شهر أغسطس من العام 2008 م. 
الوسطي حول الساحة السماوية) تتجمع عدة فراغات من خمس إلى ست غرف وتكون جميعها وحدة

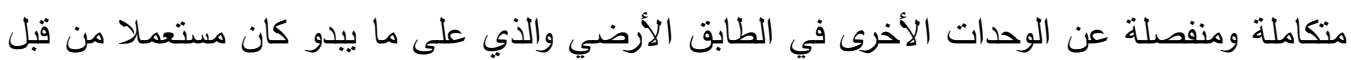

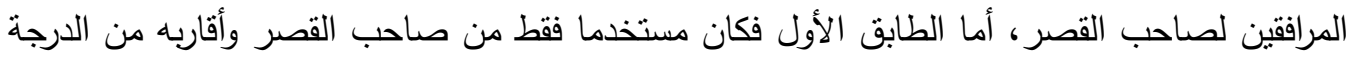

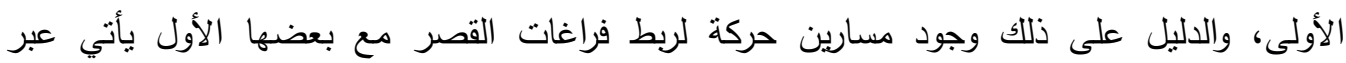

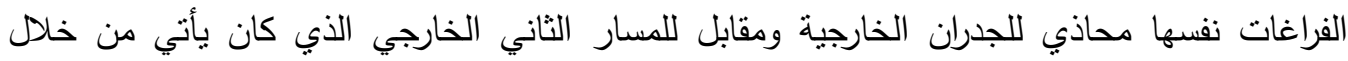
الرواق المنهار في داخل الساحة السماوية كما يظهر من وجود أبواب القاعات الرئيسية للبيوت المطلة على الساحة، تمت دراسة إعادة بناء البورتكو بالرسم الهندسي وذلك بالاعتماد أولا على نتائج الحفرية الأثرية التي قام بها ستيفن يوريس وثانبا بالاعتماد على الدائل الهندسية المتنقية في جدران الساحة الاخلية للقصر (انظر الثكل رقم 3). يأتي الاتصال العمودي في داخل القصر عبر درجين (الواحد منهما بعرض 120 سم) موجودين بين الجناح الجنوبي (في الطابق الأرضي يفصلا الإسطبلين الكائنين حول بهو المدخل) والجناحين الثرقي داني والغربي المستخدمين للسكن، ويعمل الدرجين كفاصل مادي ووظيفي بين أجنحة الطابق الأول. يوصل الإنل الدرجين إلى السطح حيث يمكن أن يستمتع الناظر من هناك بمنظر خلاب وبأفق لا منتهي.

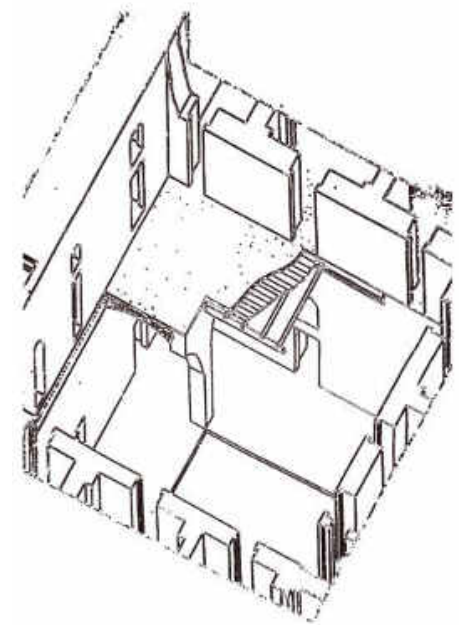

شكل رقم 3. مقترح تصوري من قبل المؤلف لإعادة بناء الرواق المتهم داخل الساحة السماوية المفتوحة في القصر، بناء؛ على دراسة الداثل الأثرية والمعمارية.

في بيت الدرج وفي منطقة البسطة نوجدا دورتا الماء(الخلاء). كما يوجد نظام لتصريف المباه في القصر عبر فتحات ومصارف في أرضيات قاعات الطابق الأول. 
والنظام الأكثر أهمية في القصر هو نظام التهوية القائم على وجود في فرق الضغط الجوي داخل وخارج فراغاته ولذا تم اختبار مساحات الفتحات بعناية مما يحدث حركة شفط قوي للهواء القادم من الجهة

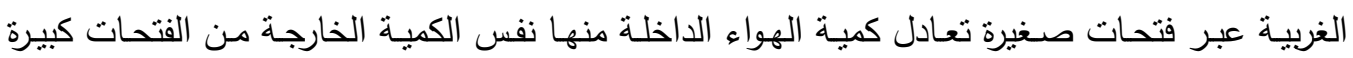

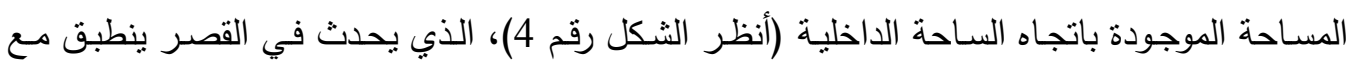

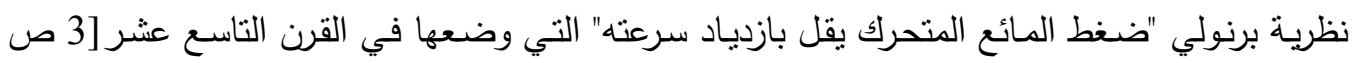
102] وما يعرف بتأثير برنولي (Bernoulli effect).
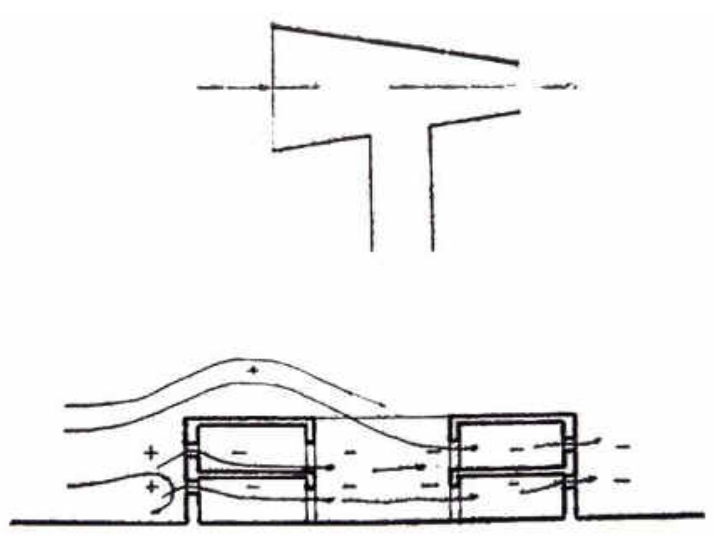

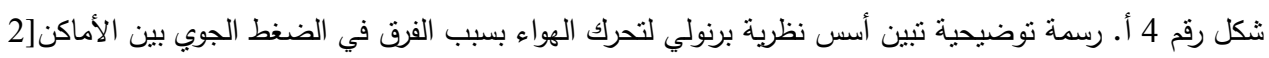
ص159]. 3ب. قصر الخرانة دراسة نطيقية لعمل شفط الهواء من خلال الفتحات الصغيرة.

التراكم التاريخي للقصر بدراسة الدلائل المعمارية فيه تقنيات الإنشاء واستخدام المواد وطرق الزخرفة جاءت على نظامين مختلفين عن بعضهما مما يؤكد وجود تراكم تاريخي لفترتين منتاليتين لبناء القصر . أ. تقنيات البناء واستخدام المواد: تم استخدام نظامين بناء مختلفين وبمواد مختلفة الواحد عن الآخر مما يؤكد أن بناء القصر جاء على القي

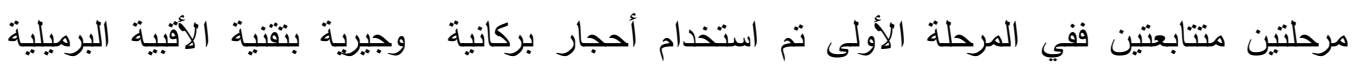
المنخفضة وكلها حجرية محمولة على أقواس مستعرضة مبنية بنفس القطع الحجرية وهذه الأقواس

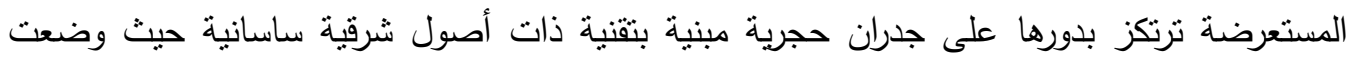

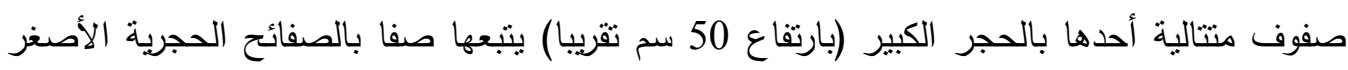

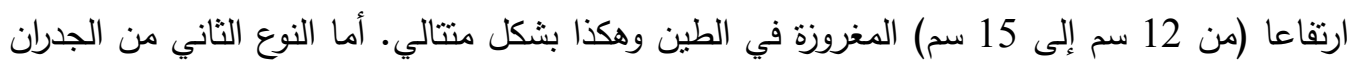
والأقواس المستعرضة والأقبية (الذي استخدم في المرحلة الثانية للبناء) فجاء على شكل خليط من الحجر 
الجيري الأبيض اللون والطين المستخرج من وادي الخرانة القريب، وهذه الثقنية ما زالت مستعملة في

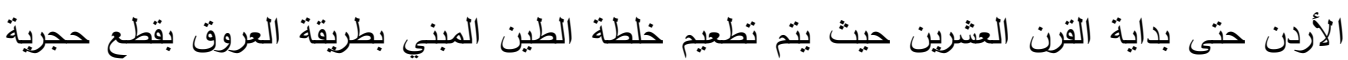

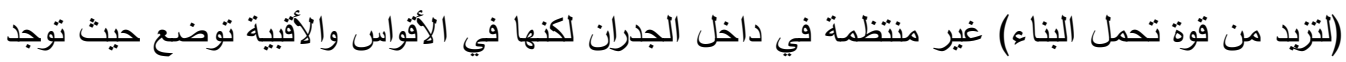
إجهادات الضغط الأعلى ومن المؤكد إضافة مادة الجير للخطة الطينية ليعطيها تماسك وعازلية للماء أكبر •

وبتتبع هذا التغير في التقنية والمواد نستطيع أن نحدد ما ينتمي للمرحلة الأولى وما ينتمي للمرحلة الثانية

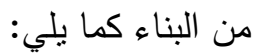
الطابق الأرضي والجناح الغربي من القصر ينتميان للمرحلة الأولى بينما استكمال التنقيف في الجناحين الجنوبي والثرقي فيعودان للمرحلة الثانية. الغريب أن موقع تغير تقنية البناء ومواده في قصر الخرانة، كما يظهر في واجهات القصر من الخارج،

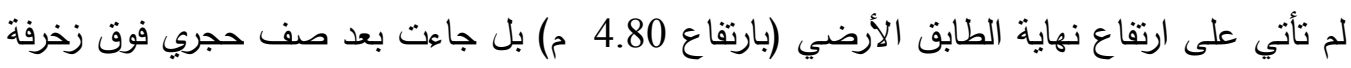

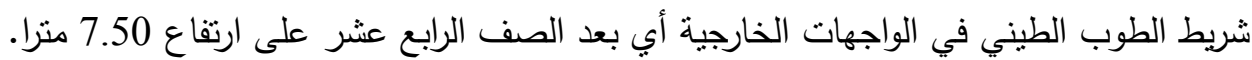

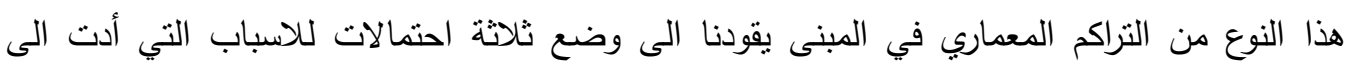

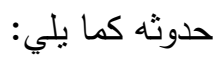
الأول: أن المواد المستخدمة لبناء المرحلة الأولى قد نفذت فاضطر المعلم بالاتفاق مع المالك إلى استخدام تقنية مختلفة وبمواد أخرى اقل تكلفة وأكثر تواجدا. الثاني: أن العادة في بناء الدور كانت تقتضي إكمال الذروة فوق الطابق وبارتفاع 270 سم ولعل الدليل على ذلك التراس المتبقي من القصر في الجناح الثمالي حيث تثبت الصور التاريخية انه بقي على

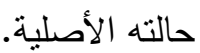
الثالث: من الممكن أن يكون قد توفي صاحب القصر ولم يكتمل بنائه (للطابق الأول) فأكمله من تبعه في امتلاك القصر بالبناء بتقنية ومواد جديدة، ليظهر ذلك ويعرب عن عن شخصية المالك الجديد والتدليل على إكتمال المبنى في عهده. من الدراسة للثلاث فرضيات الواردة يبدو أنه من الصعب بداية ترجيح أحداها على الأخرى ولكن بالاستعانة بدراسة النظام الزخرفي يمكن ترجيح احد الفرضيات على الاخرى.

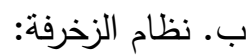

من تحليل نظام الزخرفة في القصر يبدو واضحا وجود نظامين مختلفين والرابط بينهما فقط الثنكل الدائري (انظر الثكل رقم 5)، وهذا دليل آخر على أن التغيير في المواد والتقنيات الإنثائية تبعت تغييراً

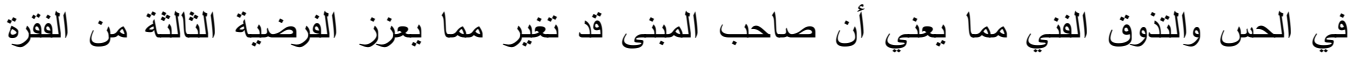


السابقة أي أن صاحب المبنى الذي بدأ في بناء القصر قد توفي قبل إنهاء المبنى وأكمله من خلفه في الملك بالبناء بتقنيات ومواد جديدة وبنظام زخرفي جديد.
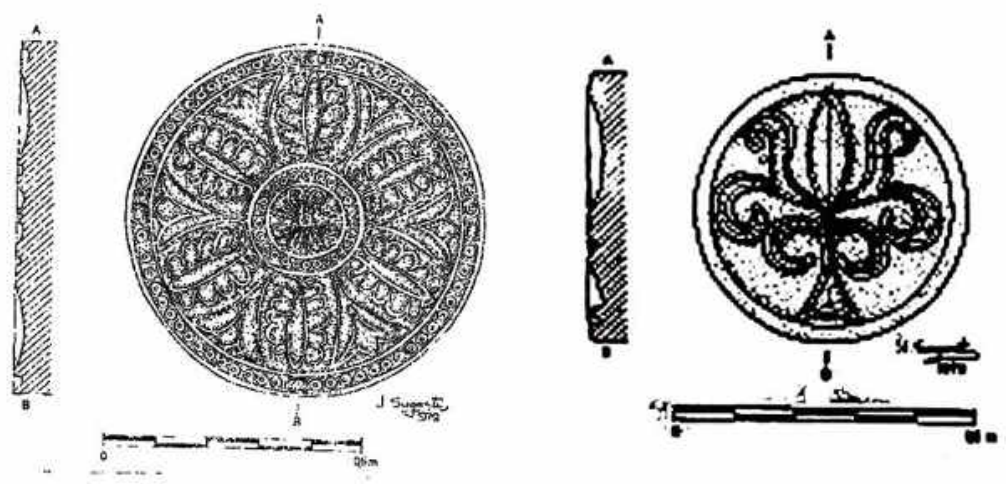

\section{شكل رقم 5 أ،ب الثكلين الزخرفيين المستخدمين في مرحلتي بناء القصر ، نثابه في الثكل الدائري واختلاف في المادة الزخرفية [1 ص 73 ]}

من خلال استقراء تاريخ وأحداث مرحلة حكم بني أمية [4]5، التي بني فيها القصر، يظهر بأن بناء

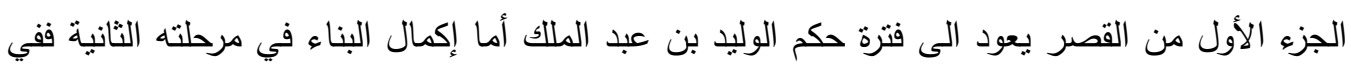
أغلب تقدير يعود الى فترة حكم بزيد الثاني بن عبد الملك. ومن خلال الرجوع للكتابات في الجناح الغربي من الطابق الأول (بناء من المرحلة الأولى) يثبت أن

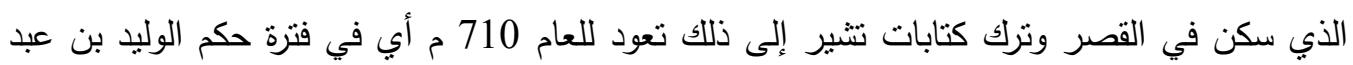

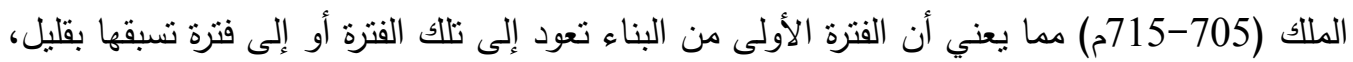

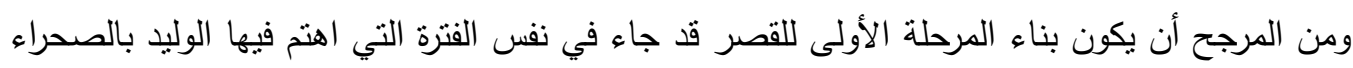

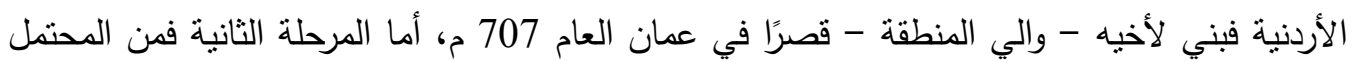

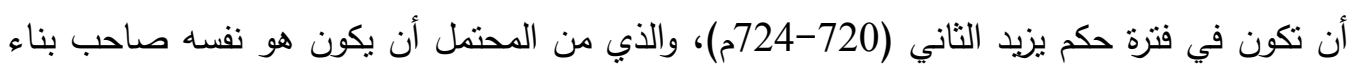

قصير عمرة القريب من الخرانة والذي بني بنفس التقنية المستخدمة في المرحلة الثانية لقصر الخرانة. وهذا منطقي، ويتجانس مع ما سارت إليه الأحداث في تلك الفترة، حيث أن ضعف الدئ الدولة وضعف

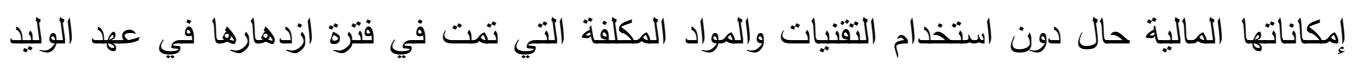

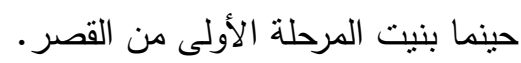

ترميم دائرة الآثار العامة والمواثيق العالمية: 5 من خلال كتب التاريخ مثل كتاب ابن كثير. البداية والنهاية في التاريخ، دار السعادة. القاهرة، 1930 م. 
كانت تعتمد أعمال الترميم في دائرة الآثار العامة في السبعينات من القرن الماضي (حين تم ترميم قصر الخرانة وفي فترة ندرة وجود المتخصصين من مرممي العمارة التاريخية والآثار ) على إصلاحات العات عثوائية لا تفي بالغرض نقوم على قاعدة الفزعة الغير ممنهجة فكلما اشتكى من القصر جزء أو آل آل للسقوط

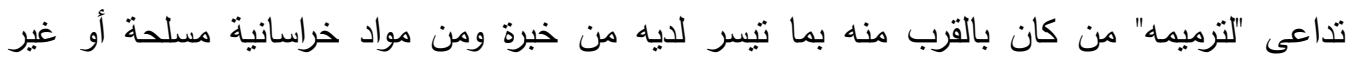
مسلحة. أوضح مثال على ذللك ما تم على سطح القصر من وضع خلى خلطة خراسانية بسماكة تتجاوز

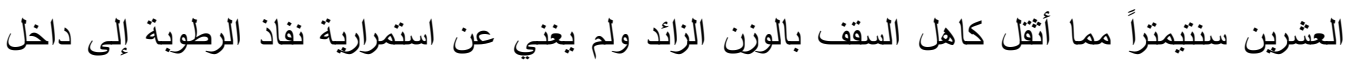
جدران وفراغات القصر (انظر الشكل رقم 6).

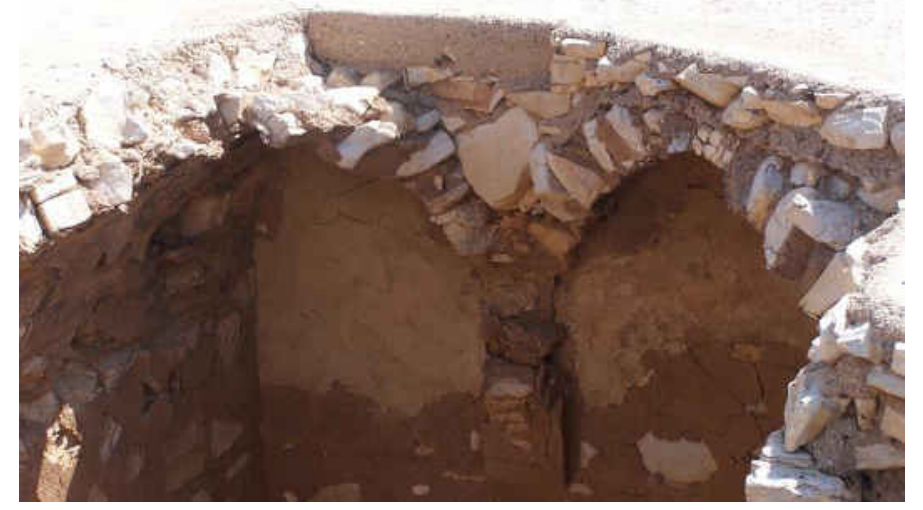

شكل رقم 6 أ. قصر الخرانة، الخلطة الخراسانية القوية والسميكة على سطح القصر وأسفل منها المواد الأصلية الضعيفة المتردية.
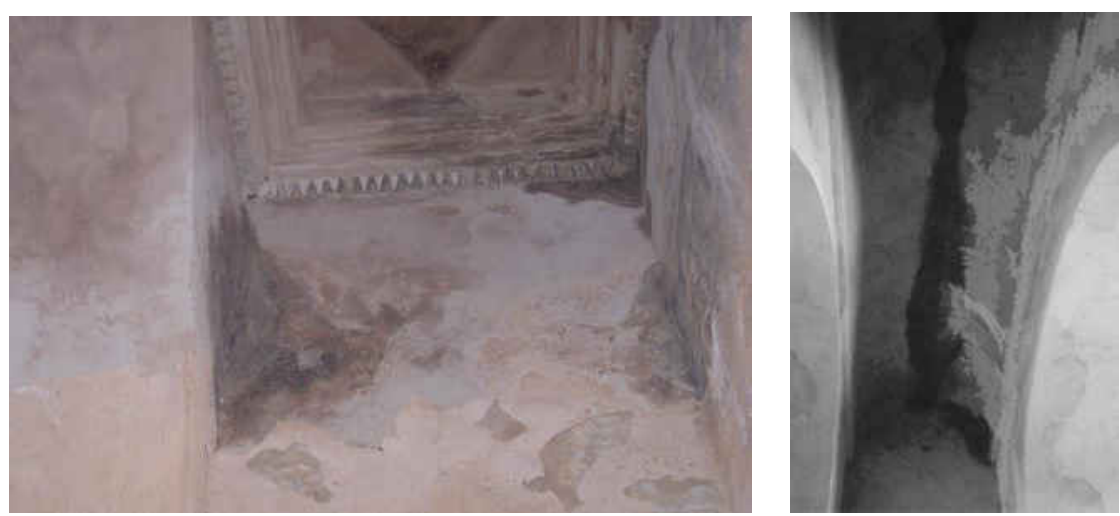

الثكل رقم 6ب، ج. قصر الخرانة، أسقف فراغات في الطابق الأول تعاني من مظاهر تلف متعددة متل نفاذالرطوبة ووجود ظاهرة تزهر الأملاح والتعفن في بعض الأجزاء داخل القصر. 
الغريب في متل هذه الأعمال أن القائمين عليها يظنون أنهم يحسنون صنعا ويدافعون عنها بقناعة أن

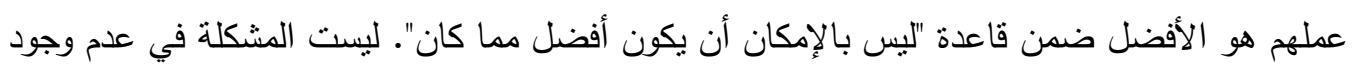

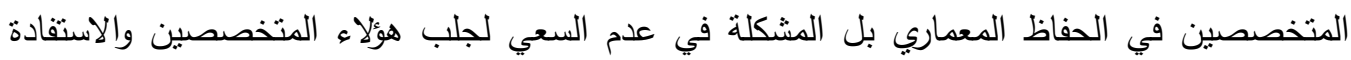
منهم إن وجدوا. لا بد بداية من تحليل ومعرفة الوضع الراهن والمشاكل الإنثائية ومشاكل المواد وأسباب المشاكل وإيجاد الحلول لها. الايجابية الوحيدة للترميم الذي نم على القصر هو المحافظة على أجزاء القصر هنماسكة مع بعضها

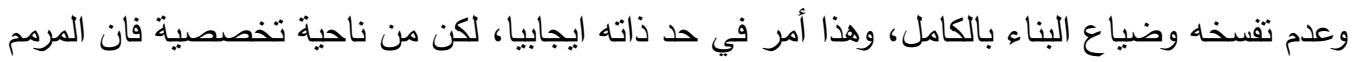

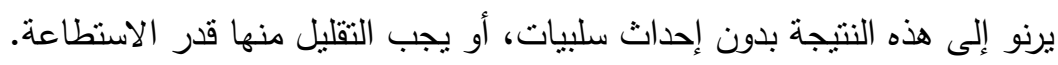

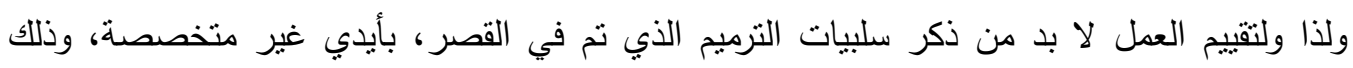

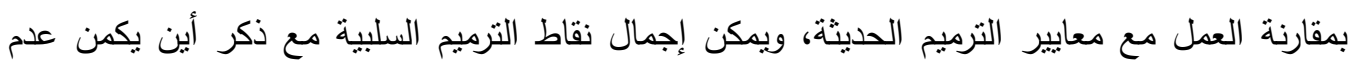

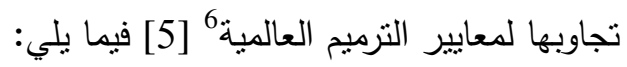

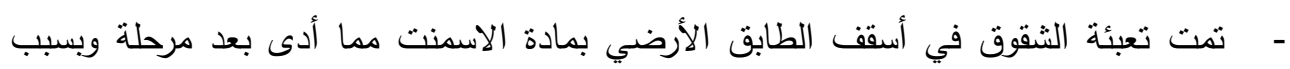

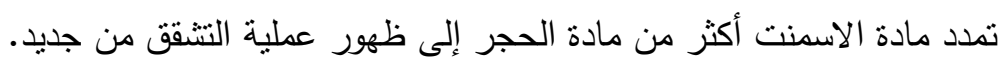

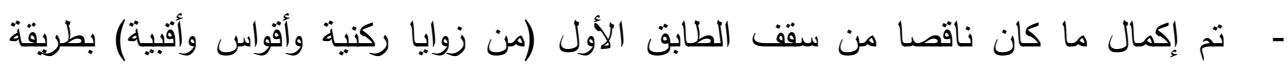

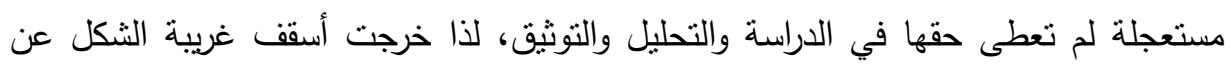

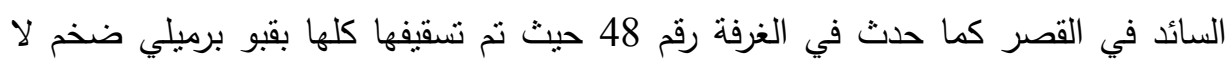

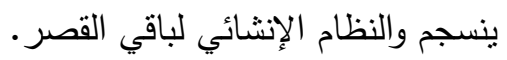
- لاستكمال الجزء الأعلى المفقود من الطابق الأول في القصر نم استخدام مواد حجرية مع خلطة إسمنتية مبالغ في وزنها وفي نسب كمية الحجارة إلى الخلطة بعكس النسب الموجودة في لإني خلطة الطين مع الحجر الأصلية "أقل تدخل ممكن". هذا سيؤدي على زئل زيادة الاجهادات الضاغطة على الجدارن القديمة أسفل منها. - إضافة المواد الخرسانية ذات التحمل الأكبر لعوامل التعرية فوق مواد ضعيفة (من الطين

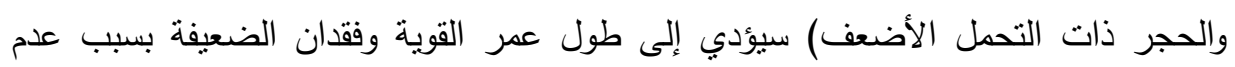
التجانس بينهما وسيتم توجيه وتركيز كل عوامل الضعف على المادة الأقل قوة.

6 تؤخذ معايير الترميم المعماري العالمية كمرجع عام لاعمال الترميم ونوجد في المواثيق العالمية والتي هي عبارة عن نتائج

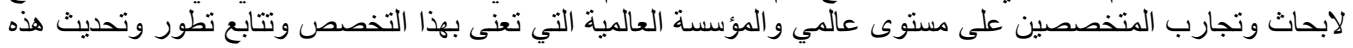

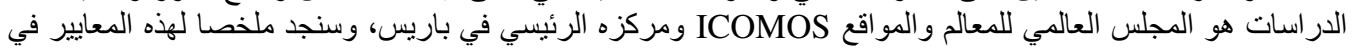

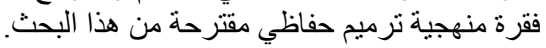


- تدخل على السطح بخلطة إسمنتية مطعمة بقطع حجرية وبسماكة كبيرة (بين 20 و 25 سم) والنتيجة أن عملية التزميم جاءت غير منعكسة (أي لا يمكن ازالتها). - مادة الاسمنت تحتوي على أملاح معدنية وبسبب ذوبانها في مياه الأمطار ستنتقل كمحلول

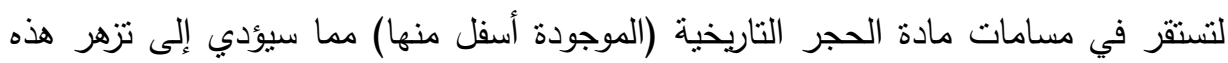

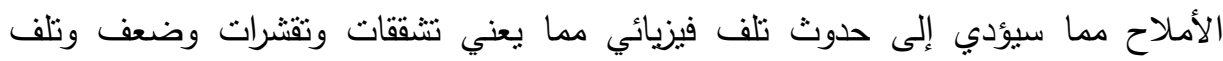
للحجر - - إغلاق الباب في الواجهة الشرقية دون الاعتماد على دراسة لتاريخ وطرق استخدام القصر

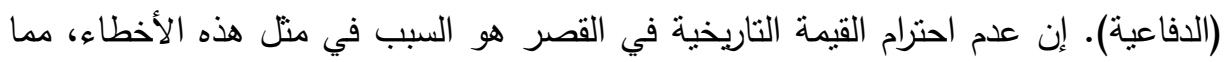

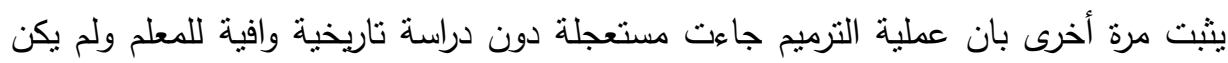
الهدف الأساسي منه الحفاظ على تللك القيمة التاريخية فيه.

المتخصص في الحفاظ المعماري كيف نحدد من هو المتخصص في الحفاظ المعماري؟ وما الفرق بينه وبين المتخصص في الحفاظ الأثري؟ وما العلاقة بين كل من اصحاب هذين التخصصين؟ حسب ما جاء في المادة الثانية من ميثاق البندقية الصادر عام 1964 فان "الحفاظ والترميم للمعالم

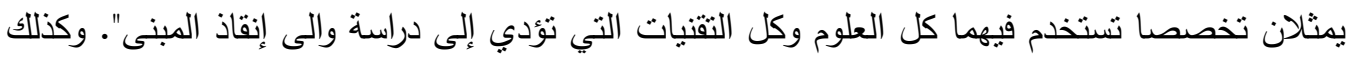

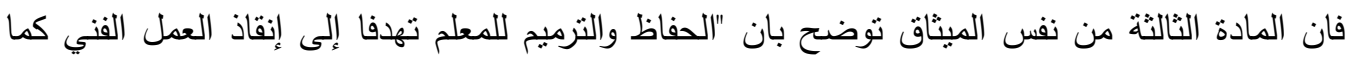
تهدفا أيضا لإنقاذ الدلائل التاريخية". أما الحفاظ الأثري (كفرع تخصصي من الحفاظ المعماري) فيقوم بربط المعرفة بالتاريخ وبالمادة وبالقيم الأثرية للموقع، وكما جاء في المادة الثامنة (تحت عنوان النوعية المهنية) من الميثاق الدولي لإدارة

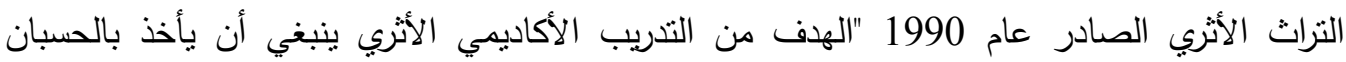
التغيير في سياسة الحفاظ من الحفرية الأثرية إلى الحفاظ الوقائي في المكان". من ذللك يتضح أن التخصصين مكملان لبعضهما ولا بد من نوافق الجهود ومن تكاملها في أعمال

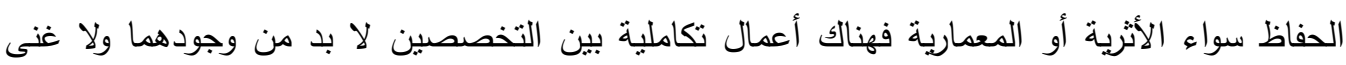

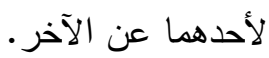

\section{منهجية ترميم حفاظي مقترحة}

الترميم الذي توصي به المواثيق العالمية7 [6، 7] الصادرة عن الإيكوموس وخاصة ميثاق البندقية تركز على دفهوم الترميم الحفاظي [6 ص 114-115. 7 ص 22-23] بمعنى أن الهدف من الترميم هو 
الحفاظ على القيم الثقافية والاجتماعية في القصر وكذلك الحفاظ على المادة المكونة لعناصر المبنى التاريخي، أي يجب على الترميم أن يحافظ على أصالة المعلم، فلا يحدث فيها أي تغيرات بالاعتماد

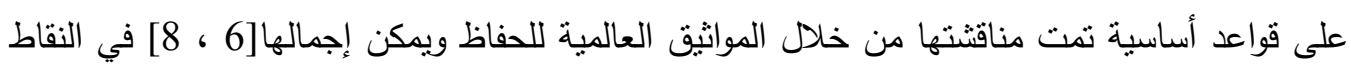

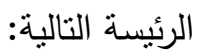

- - التمييز بين المواد المضافة والمواد الأصلية من خلال النظر بالعين المجردة وعن قرب.

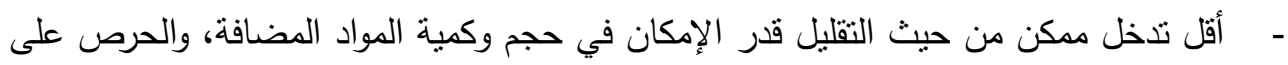
عدم إزالة المواد الأصلية.

- التجانس بين المادة المضافة والمادة الأصلية كيمائيا وفيزيائيا وشكليا ولونيا.

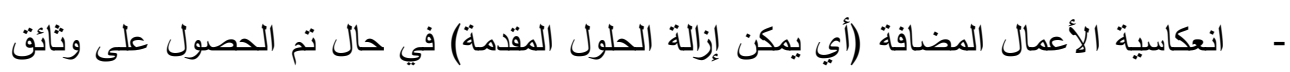
لحلول أكثر صحة. - أن لا يغير التذخل في شكل وحجم المبنى الأصلي خارجيا من إضافة أو نقصان ولا داخليا من حيث التلاعب في الفراغات المعمارية الداخلية. وبناء على هذا المنطلق يتم تقديم هذا المقترح لترميم قصر الخرانة على أمل أن تجد هذه الدراسة صدى فلئ

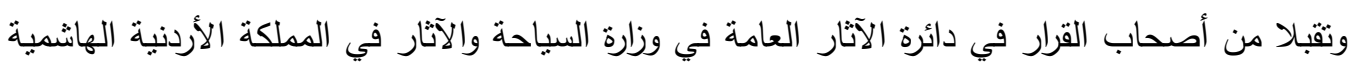

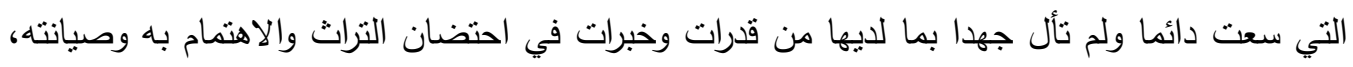

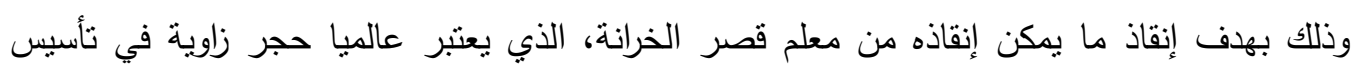
وتأريخ عمارة المسلمين، وفهم العناصر الحضارية لتلاك الفترة الذهبية في فترة نشأنها. يقوم المقترح على تحقيق النقاط الرئيسية التالية: - دراسة المشاكل الإنشائية ومعرفة أسبابها وتقديم حلول لها، وخاصة بما يتعلق بالإضرار الوقعة

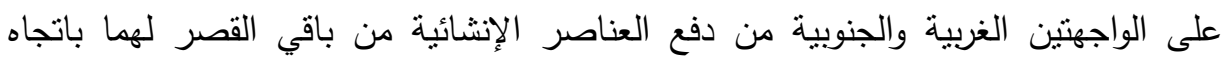

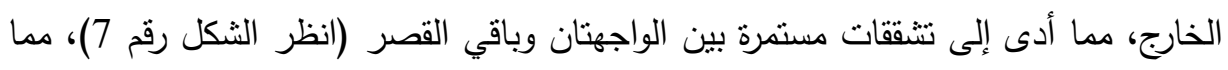

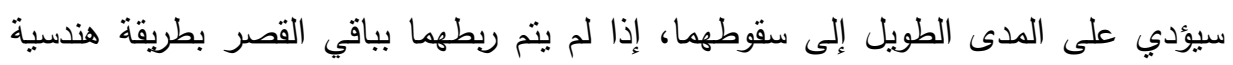
سليمة وصحيحة.

\footnotetext{
- جمال عليان. الحفاظ على التراث الثقافي. نحو مدرسة عربية للحفاظ على التراث الثقافي وإدارته. سلسلة كتب عالم المعرفة

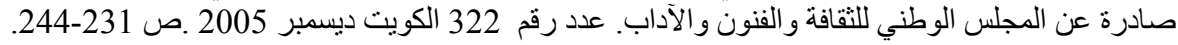

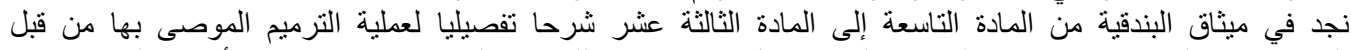

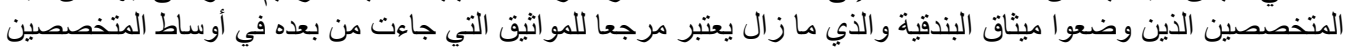

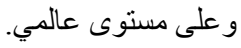




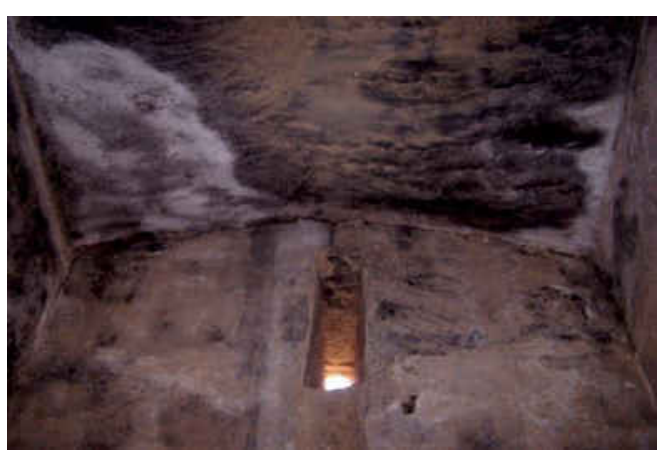

الثكل رقم 7, قصر الخرانة، شقوق مستمرة بين الواجهة الجنوبية وباقي القصر

- التخلص بقدر الإمكان من خلطات الاسمنت المضافة على سطح القصر دون الإضرار بالعناصر والمواد الإنشائية الأصلية، والعمل على عزله ضد الإمطار بطريقة لا تؤذي المواد الأصلية. - ـ ـ إكمال الرواق (العنصر المعماري) المتهام من القصر، في وسط الساحة الداخلية السماوية،

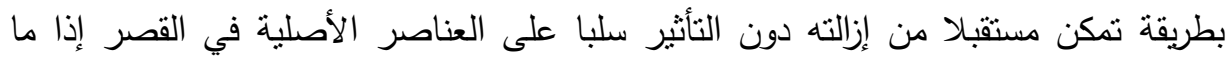

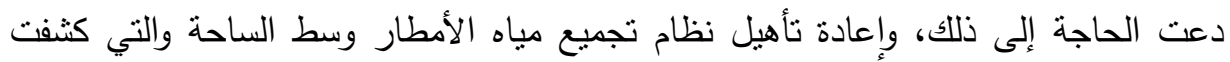

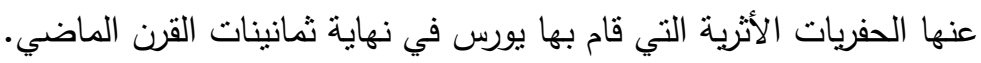
- - إعادة فتح الباب في الواجهة الثرقية كما كانت قبل تدخل الترميم من سبعينات القرن الماضي.

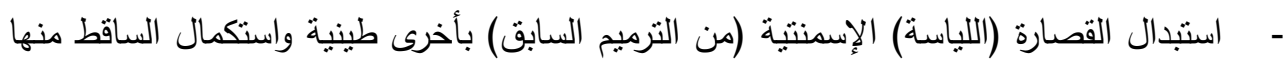

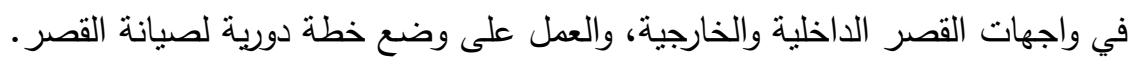
- ترميم العناصر الزخرفية الخارجية (شريطا الطوب الطيني والألواح الجصية فوق مدخل القصر ) والداخلية (الأقراص الزخرفية الجصية بنوعيها من مراحل البناء). - - ترميم العناصر المعمارية الداخلية (الأقواس والزوايا الركنية والأقبية) بشكل لا يشوهها منها ويحافظ عليها. إعطاء الباب الخشبي الحالي لون داكن يتجانس مع لون الباب القديم الذي ظهر في صور

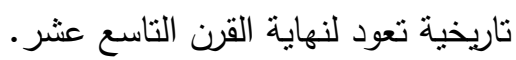
- إعادة استخدام القصر (تم تقديم مقترح من خلال دراسة سابقة لإعادة تأهيله كمتحف للحضارة الأموية [9 ص 903-911]) مما يضمن استمرارية القيام بالصيانة الدورية ويساعد في الحفاظ 
هذه الأعمال في مجملها، والتي ستضمن لنا سلامة المعلم واستمرارية وجوده، لن تكون تكلفتها المالية بأعلى من تكلفة المبنى الذي تم بنائه مؤخرا كمركز للزوار بالقرب من القصر (انظر الثكل

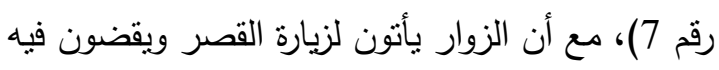

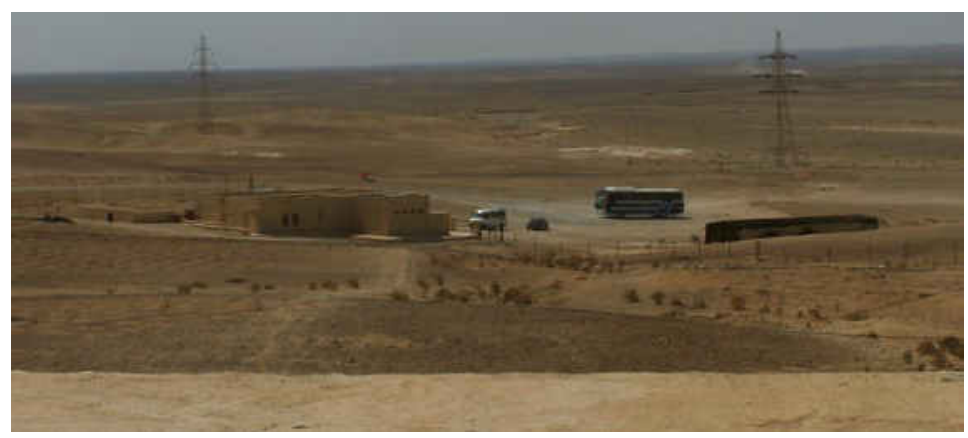

شكل رقم 7. صورة من فوق قصر الخرانة باتجاه مركز الزوار المبني مؤخرا على مقربة من القصر

أضعاف الوقت الذي يقضونه في الاستراحة، وكان بالإمكان تأجيل وتأخير بناء الاستراحة وتعجيل عملية الترميم والحفاظ للقصر، خاصة وان خيمة الزوار السابقة (بيت الثعر ) كانت قائمة بمهمة استقبال زواره لعشرات من سنين قد خلت.

النتائج والتوصيات:

يمكن إجمال نتائج وتوصيات البحث فيما يلي: - بنيت القصور الأموية بين دمشق والحجاز وجنوب العراق ضمن نظام استراحة القوافل للمسيرة البومية، وهذا يفتح المجال للبحث عن القصور المندثرة من ذلك النظام. - قصر الخرانـة وأمثاله من قصور بني أمية التي كانت تربط الثـام بالعراق وبالجزيرة العربية

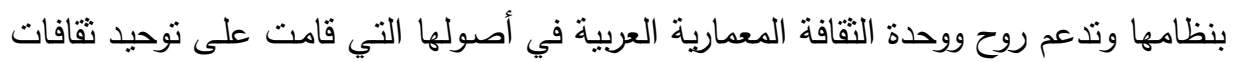
متتاحرة مسبقا الساسنية الثرقية والبيزنطية الغربية في بوتقة إسلامية جديدة.

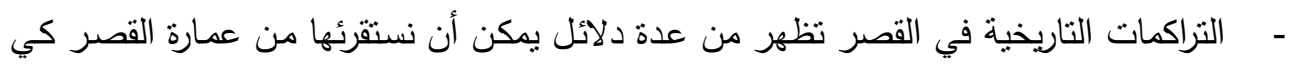
نسنطيع صياغة قصة وتاريخ المعلم. ليست المشكلة في عدم وجود المتخصصين في الحفاظ المعماري، بل المشكلة أولا في عجز المعارئ

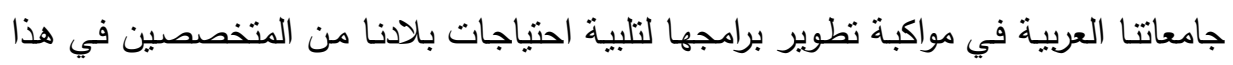

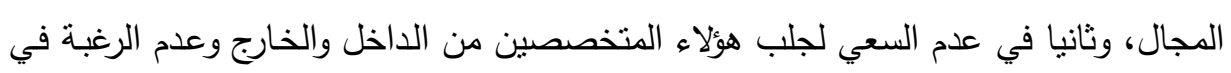
الاستفادة منهم إن وجدوا. 
- يحتوي القصر على قيم ثقافية متعددة منها القيمة العلمية مثل ما هو الحال في نظام التهوية

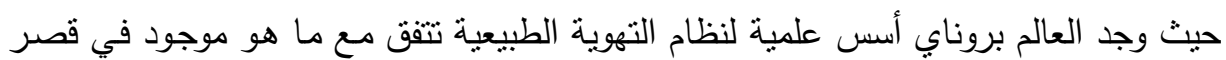
الخرانة بعشرات القرون تسبق اكتثاف برنولي.

- استقراء قصة وتاريخ المبنى من خلال تحليل النظام الانشائي المعماري وطرق الزخرفة

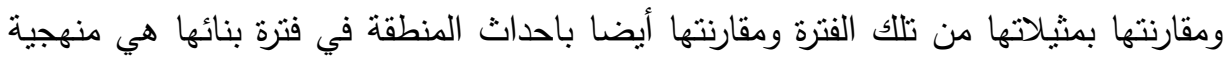
في التاريخ نلجأ لها في حين عدم وجود ونائق تاريخية نعتمد علينها. - الهدف الأساسي من الترميم هو الحفاظ على القيم الكامنة فيه (تقافية واجتماعية) وعلى مواده الأصلية المكونة له (الحفاظ على الأصالة).

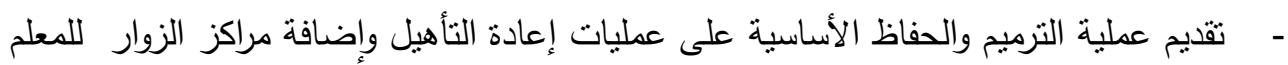

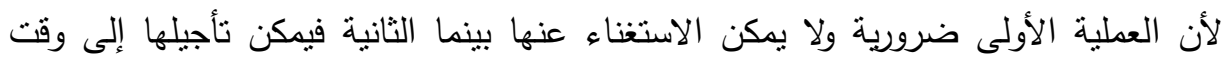
لاحق إذا قضت الضرورة. - منهجية الترميم المقترحة تعكس المواثيق العالمية في الحفاظ، واسس الترميم، كما تعكس فهم المعلم بتراكماته التناريخية وقيمه التقافية.

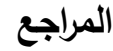 www.jordan map.com موقع [1]}

[2] Urice. Qasr Kharana in the Transjordan. American school of Orienta Research. Durham, 1989. p.44.

[ 3] حسن فتحي. الطاقات الطبيعبة والعمارة الثقليدية. جامعة الأمم المتحدة طوكيو ـ المؤسسة العربية للاراسات والنشر 1986. [4] ابن كثير ـ البداية والنهاية في التاريخ، دار السعادة. القاهرة، 1930 م.

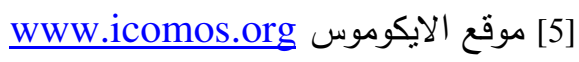
[6] جمال عليان. الحفاظ على التنراث الثقافي. نحو مدرسة عربية للحفاظ على التراث الثقافي وإدرتهـ. سلسلة كتب عالم المعرفة صادرة عن المجلس الوطني للنقافة والفنون والآداب. عدد رقم 322 الكويت ديسمبر 2005 .ص 231-244.

[7] جمال عليان العمارة بين ركائز الحفاظ وقوى التجديد. مجلة القطاع الهندسي لجامعة الازهر

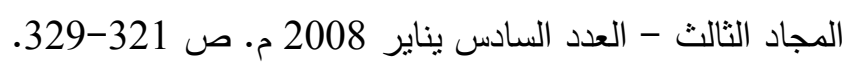

[8] G. Carbonara. Trattato di Restauro Architettonico. UTIT, Torino 1999 pp. 22-23

[9]J. Ilayan. New Presentation "System" of Umayyad Desert Castles in Jordan. Integrated museum of Umayyad Civilization. Al Azhar University Engineering Journal. Vol. 9, No.3, Cairo Julay 2006. pp. 903-911. 